\title{
Research progress in human infection with avian influenza H7N9 virus
}

\author{
Jing Tang \& Dayan Wang* \\ National Institute for Viral Disease Control and Prevention, Chinese Center for Disease Control and Prevention; WHO Collaborating \\ Center for Reference and Research on Influenza; Key Laboratory for Medical Virology, National Health and Family Planning Commission, \\ Beijing 102206, China
}

Received October 9, 2017; accepted November 6,2017; published online December 1, 2017

\begin{abstract}
Since the identification of the novel reassortant avian influenza A (H7N9) virus in China in 2013, until Jun 30, 2017, the virus has caused five epidemic waves leading to a total of 1,552 human infections, with a fatality rate of about $40 \%$. In the spring of 2017, highly pathogenic avian influenza (HPAI) H7N9 virus emerged and has caused 25 human infections. The HPAI H7N9 virus has some biological differences from the LPAI one, such as its multiple basic amino acid residues on HA leading to its independence on trypsin for replication. The pathogenicity of the HPAI H7N9 virus to experimental animals or humans is still unclear. A(H7N9) vaccine development for pandemic preparedness is ongoing, including the reassortment (H7N9/PR8) reverse genetic based vaccine, the virus like particle (VLP) vaccine, the intranasal live attenuated influenza vaccine (LAIV), the non-adjuvant Vero cell culture-derived inactivated whole-virus vaccine, the MDCK culture-derived vaccine, the H7 DNA vaccine and the recombinant replicative H7N9 virus $\backslash(\mathrm{H} 7 \mathrm{~N} 9-53 \mathrm{TM} \backslash)$ vaccine. Five neuramidinase resistant sites of $\mathrm{A}(\mathrm{H} 7 \mathrm{~N} 9)$ virus isolated from patients have been reported. Some alternative drugs have been studied, such as DAS181 (Fludase), ribavirin, troglitazone and minocycline. Persistent surveillance and enhanced global control are essential to fight against human infections with $\mathrm{A}(\mathrm{H} 7 \mathrm{~N} 9)$ virus.
\end{abstract}

influenza $A(H 7 N 9)$ virus, epidemiology, virological characteristics, vaccine, drug resistance

Citation: Tang, J., and Wang, D. (2017). Research progress in human infection with avian influenza H7N9 virus. Sci China Life Sci 61, 1299-1306. https://doi.org/10.1007/s11427-017-9221-4

\section{INTRODUCTION}

Although avian influenza $\mathrm{H} 7$ subtype viruses such as $\mathrm{H} 7 \mathrm{~N} 1$, H7N2, H7N3 and H7N7 have sporadically infected humans worldwide, they have never caused human infections with a big fatal outcome until the outbreak of H7N9 in 2013 (Qi et al., 2013; Richard et al., 2013; Shi et al., 2013). Human infections with N9 subtype viruses had never been reported before 2013. Since the notification of human infection with novel reassortant influenza A(H7N9) virus on 31 March 2013, in total 1,552 laboratory-confirmed cases have been reported to

*Corresponding author (email: dayanwang@cnic.org.cn)
WHO (http://www.chinaivdc.cn/cnic/en/Surveillance/WeeklyReport/201706/t20170630_144621.htm). Avian influenza $\mathrm{H} 7 \mathrm{~N} 9$ virus was recognized as easier to infect mammals and caused the largest number of human infections, more than other previously reported avian influenza viruses did, including H5N1 (Zhou et al., 2013). What is more, in the spring of 2017, a significant mutation in the Hemagglutinin of H7N9 was observed during the surveillance system (Yang and Liu, 2017; Zhang et al., 2017; Zhu et al., 2017). The presence of multiple amino acids in the cleavage site indicates that the H7N9 has evolved from LPAI virus to HPAI virus. This review will discuss the epidemiology, viral characteristics, vaccines and drug resistance of H7N9 virus. 


\section{EPIDEMIOLOGY}

In March 2013, China reported first human infection with novel reassortant avian influenza H7N9 virus, the first three cases were from Shanghai municipal city and Anhui province, respectively (Gao et al., 2013). This first epidemic resulted in 134 laboratory confirmed cases within 6 months. Over the next few years, the feared pathogen has caused another four epidemic waves. There are 306, 219, 114 and 779 laboratory-confirmed cases respectively in the later successive four winter-spring epidemics (http://www.chinaivdc.cn/cnic/en/Surveillance/WeeklyReport/201706/t20170630_144621.htm) (Wang et al., 2017a), including three cases acquired infection in mainland China and exported to other countries (Malaysia and Canada). The fifth epidemic wave that started on Oct 1, 2016, has included 779 laboratory-confirmed cases in mainland China just as Figure 1 showed (as of Jun 30, 2017) (http://www.chinaivdc.cn/cnic/en/Surveillance/WeeklyReport/201706/t20170630_144621.htm; http://www.who.int/influenza/human_animal_interface/ HAI_Risk_Assessment/en/), and is the largest epidemic wave so far. No increased risk of human-to-human transmission was identified (http://www.chinaivdc.cn/cnic/en/Surveillance/WeeklyReport/201706/t20170630_144621.htm), so the increased number of human infections in the fifth wave may be associated with wider geographic spread and higher prevalence of $\mathrm{A}(\mathrm{H} 7 \mathrm{~N} 9)$ viruses circulating in poultry in China. Since 2013, the first four wave outbreaks have been caused by LPAI H7N9, and LPAI H7N9 is not pathogenic in poultry, which poses challenges to the prevention and control of H7N9.LPAI H7N9 virus might be undetected in poultry farms, and wholesale and retail markets, unless active surveillance is conducted. Another reason for the geographical expansion may be that the closure of the live poultry market in the affected areas has led to the transportation of infected poultry to other areas.

The epidemiological distribution of the five wave H7N9 epidemics is shown in Table 1. Cases were concentrated in the Yangtze River Delta in eastern China. The median age of laboratory-confirmed human infections with A(H7N9) virus is about 58 years, the case fatality rate of $\mathrm{A}(\mathrm{H} 7 \mathrm{~N} 9)$ influenza virus is approximately 40\% (Wang et al., 2017a). Men consistently accounted for about $70 \%$ of all cases during the five epidemics (Wang et al., 2017a). This was mostly due to gender-based differences in exposure to poultry as opposed to differences in immunity (WHO. (2013). Overview of the Emergence and Characteristics of the Avian Influenza A (H7N9) virus. Geneva: World Health Organization). Additionally, older men were found to be weaker than older women due to their shorter mean life-span (Zhuang et al., 2013). Estrogen had been suspected to be the protective agent and mice experiments have been done, but failed to prove this guess (Hoffmann et al., 2015).

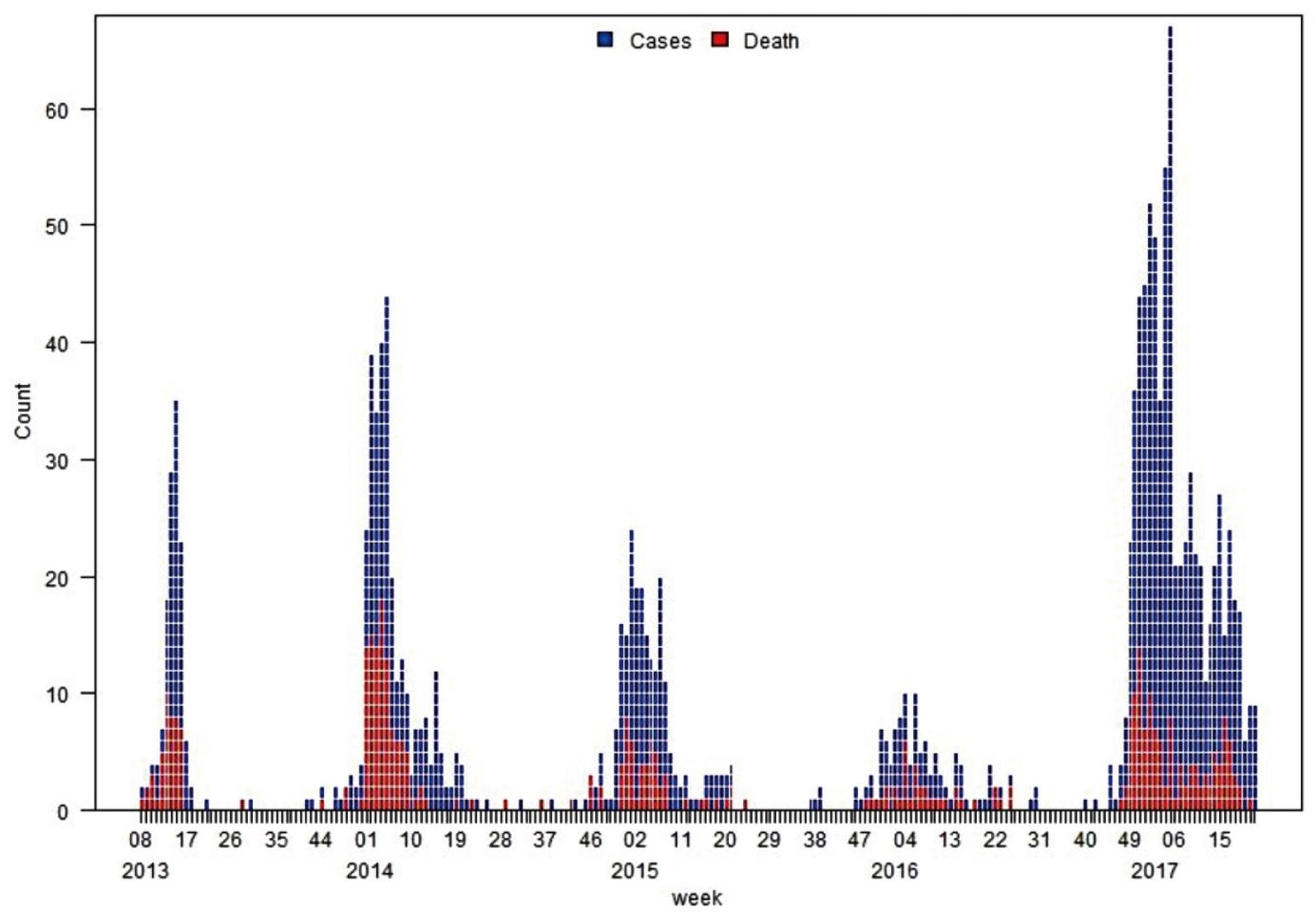

Figure 1 Number of laboratory-confirmed human H7N9 cases and death in mainland China, 2013-2017 (http://www.who.int/influenza/human_animal_interface/HAI_Risk_Assessment/en/). 
Table 1 Characteristics of laboratory-confirmed cases of A(H7N9) virus infection in mainland China

\begin{tabular}{|c|c|c|c|c|c|}
\hline & $\begin{array}{c}\text { Epidemic 1, Jan } \\
\text { 2013-Sept 2013, } n=134\end{array}$ & $\begin{array}{c}\text { Epidemic 2, Oct } \\
\text { 2013-Sept 2014, } n=306\end{array}$ & $\begin{array}{c}\text { Epidemic 3, Oct } \\
\text { 2014-Sept } 2015, n=219\end{array}$ & $\begin{array}{c}\text { Epidemic 4, Oct } \\
\text { 2015-Sept 2016, } n=114\end{array}$ & $\begin{array}{c}\text { Epidemic 5, Oct } \\
\text { 2016-Feb 2017, } n=447\end{array}$ \\
\hline Median age (range) & $61(2-91)$ & $57(2-88)$ & $56(1-89)$ & $58(13-92)$ & $58(4-93)$ \\
\hline Men & $94(70 \%)$ & $212(69 \%)$ & $156(71 \%)$ & $77(68 \%)$ & $317(71 \%)$ \\
\hline Poultry exposure & $107(80 \%)$ & $209(68 \%)$ & $151(69 \%)$ & $83(73 \%)$ & $337(75 \%)$ \\
\hline Death & $45(34 \%)$ & $131(43 \%)$ & $102(47 \%)$ & $47(41 \%)$ & $169(38 \%)$ \\
\hline
\end{tabular}

It was reported at least $70 \%$ of laboratory-confirmed A(H7N9) human cases have exposure history to poultry within 10 days before the onset of symptoms across five epidemics (Wang et al., 2017a). Visiting a live poultry market and exposure to backyard poultry were the two major sources of poultry exposure. A nosocomial cluster induced by co-infections with avian influenza A(H7N9) and $\mathrm{A}(\mathrm{H} 1 \mathrm{~N} 1) \mathrm{pdm} 09$ ( $\mathrm{pH} 1 \mathrm{~N} 1)$ viruses occurred in two patients at a hospital in Zhejiang Province, China, suggesting limited nosocomial co-transmission of H7N9 and $\mathrm{pH} 1 \mathrm{~N} 1$ viruses from one immunocompromised patient to another (Chen et al., 2016). However, to date there is no definitive evidence on sustained person-to-person transmissions, although few family clusters were reported (Li et al., 2014; Qi et al., 2013).

HPAI H7N9 was reported in the fifth wave. Compared with all LPAI A(H7N9) case-patients reported during the fifth epidemic, HPAI A(H7N9) case-patients were significantly more likely to live in rural areas, have exposure to sick or dead poultry, and be hospitalized earlier. No significant differences were observed between LPAI and HPAI A(H7N9) in median age, sex, median time from illness onset to starting antiviral treatment, prevalence of underlying chronic medical conditions, or proportion of patients who received oseltamivir treatment, intensive-care unit admission, or mechanical ventilation (Zhou et al., 2017). It was reported that more rapid progression and greater disease severity for HPAI H7N9 casepatients, because mortality was higher and the intervals from illness onset to diagnosis and to death were shorter compared with LPAI A(H7N9) case-patients; however, these differences were not significant (Zhou et al., 2017).

\section{VIRAL CHARACTERISTICS}

Based on the first three isolated A(H7N9) viruses, A/Anhui/1/2013, A/Shanghai/1/2013 and A/Shanghai/2/2013, it was confirmed to be a novel reassortant virus, sequencing analyses revealed that the HA gene shared the highest identity with $\mathrm{A} /$ duck/Zhejiang/12/2011(H7N3). The NA gene was most closely related to A/wild bird/Korea/A14/2011(H7N9). All the genes from these three viruses were of avian origin, with six internal genes sharing the highest similarity with A/brambling/Beijing/16/2012(H9N2)-like virus (Gao et al., 2013). The internal gene of $\mathrm{A}(\mathrm{H} 9 \mathrm{~N} 2)$ has an efficient replication capacity in mammalian cells. In addition to A(H7N9), the avian influenza $\mathrm{A}(\mathrm{H} 10 \mathrm{~N} 8)$ and $\mathrm{A}(\mathrm{H} 5 \mathrm{~N} 6)$ viruses which infected humans in recent years, also possess internal genes from H9N2 virus (Jin et al., 2014).

Hemagglutinin (HA) gene sequences demonstrated two outbreak sources of A(H7N9) viruses have been established in China since 2014 (Wang et al., 2016), which are the Yangtze River delta region and the Pearl River delta region. The two outbreak sources are recognized as the source for A(H7N9) outbreaks and have been providing virus to other areas, so far majority of the A(H7N9) viruses belong to the Yangtze River delta region (Figure 2) (WHO. Increase in Human Infections with Avian Influenza A(H7N9) Virus During the Fifth Epidemic - China, October 2016-February 2017).

The HA cleavage site of vast majority of A (H7N9) virus possesses only a single amino acid $\mathrm{R}$ (arginine), indicating low pathogenic effects in poultry. Of particular note, in the fifth wave, highly pathogenic avian influenza (HPAI) H7N9 viruses were detected in 25 cases from Taiwan (with likely exposure to poultry in Guangdong), Guangdong, Guangxi and Hunan, which has an insertion of four basic amino acid residues (KRKRTAR/G or KGKRIAR/G motif) at the cleavage site connecting the HA1 and HA2 peptide regions (Yang and Liu, 2017; Zhang et al., 2017; Zhu et al., 2017). Unlike the LPAI H7N9 virus, the HPAI H7N9 virus has similar replication ability with or without trypsin indicating its trypsin independence quality (Zhu et al., 2017). It was proved that HPAI H7N9 virus maintaining the "dual receptor binding" capacity of LPAI H7N9 virus, indicating they can bind to avian-type (a2,3-linked sialic acid) as well as human-type (a2,6-linked sialic acid) receptors (Zhu et al., 2017). A most recent study showed, the HPAI H7N9 strain isolated from poultry was not lethal in mice or ferrets, but readily obtained the $627 \mathrm{~K}$ or $701 \mathrm{~N}$ mutation in its PB2 segment upon replication in ferrets, causing it to become highly lethal in mice and ferrets and to be transmitted efficiently in ferrets by respiratory droplet (Imai et al., 2017).

A(H7N9) virus can invade epithelial cells in the human lower respiratory tract and type II pneumonocytes in alveoli, and replicated efficiently in ex vivo lung and trachea explant culture and several mammalian cell lines (Zhou et al., 2013). A mouse experiment showed that Intranasal infection of mice with A/Shanghai/2/2013 (Sh2/H7N9) virus led to significant weight loss without fatality (Mok et al., 2013). This virus 


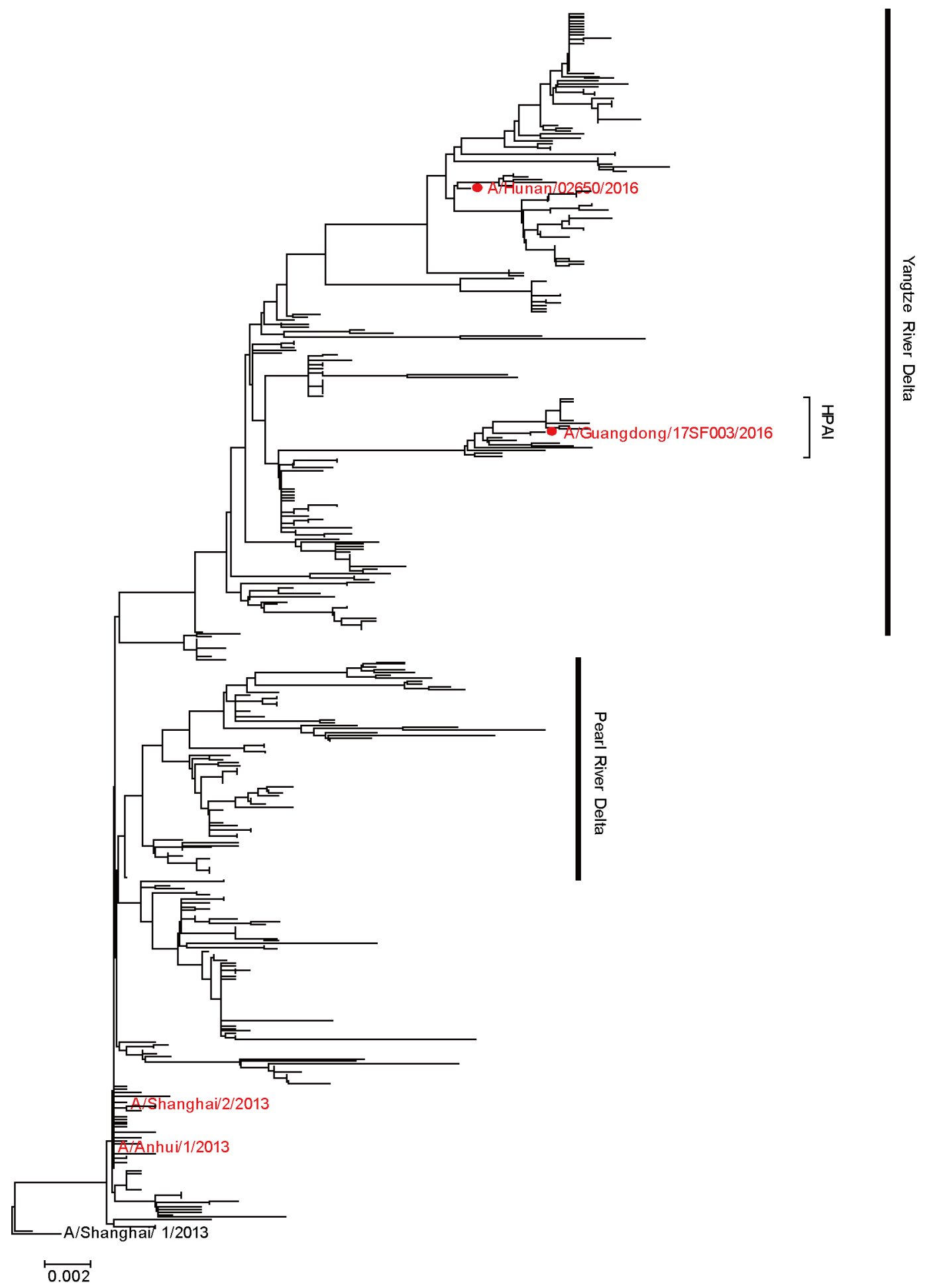

Figure 2 (Color online) Phylogenetic relationships of A (H7N9) HA genes.

was more pathogenic than A/duck/Jiangxi/3286/2009 (dk/H7N9) and A/chicken/Hong Kong/HH8/2010 (ck/H9N2) virus, which has six internal gene segments that are genetically similar to Sh2/H7N9. Sh2/H7N9 replicated well in the nasal cavity and lung, but there was no evidence of virus dissemination beyond the respiratory tract. Mice infected with Sh2/H7N9 produced higher levels of proin- flammatory cytokines in the lung and serum than did ck/H9N2 and dk/H7N9 but lower levels than HPAI A/Hong Kong/483/1997 (483/H5N1). Cytokine induction was positively correlated with virus load in the lung at early stages of infection. The results suggest that Sh2/H7N9 virus is able to replicate and cause disease in mice without prior adaptation but is less pathogenic than $483 / \mathrm{H} 5 \mathrm{~N} 1$ virus. Besides 
mouse, ferret and pig experiments have been done to study infectivity, transmission, pathology of human-isolated H7N9 influenza virus. Sh2/H7N9 replicated in the upper and lower respiratory tracts of the ferrets and was shed at high titers for 6 to 7 days, with ferrets showing relatively mild clinical signs. Sh2/H7N9 was efficiently transmitted between ferrets via direct contact, but less efficiently by airborne exposure. Pigs were productively infected by Sh2/H7N9 and shed virus for 6 days but were unable to transmit the virus to naïve pigs or ferrets (Zhu et al., 2013). Similar to what has been observed for $\mathrm{H} 5 \mathrm{~N} 1$ infections, immunopathogenetic analysis of H7N9 infection samples reveals high levels of plasma proinflammatory cytokines and chemokines, termed hypercytokinemia, in the early stage of the infection (Liu et al., 2014).

\section{VACCINES}

Vaccination is the primary measure to control the spread of influenza virus infection in humans (Song et al., 2015). The development of candidate vaccine viruses (CVVs) of zoonotic influenza, coordinated by WHO, remains an essential component of the overall global strategy for influenza pandemic preparedness. Selection and development of zoonotic influenza CVVs are the first steps towards timely vaccine production and do not imply a recommendation for initiating manufacture.

WHO recommended A/Anhui1/2013(H7N9)-like virus as CVV in May, 2013. However, some $\mathrm{A}(\mathrm{H} 7 \mathrm{~N} 9)$ virus since 2016 reacted less well with post-infection ferret antiserum raised against the available A/Anhui/1/2013 and A/Shanghai/2/2013-derived CVVs (Figure 2). Therefore, in March 2017, a new A/Hunan/2650/2016-like $\mathrm{CVV}$ is proposed by WHO. Additionally, the HPAI A(H7N9) viruses were antigenically significantly different from the 2013 CVVs. Therefore, a new CVV derived from an A/Guangdong/17SF003/2016-like virus (HPAI) is proposed (http://apps.who.int/iris/bitstream/10665/254827/1/WER9212.pdf?ua=1).

A(H7N9) vaccine based on classical reassortant platform has not been reported yet. A(H7N9) vaccine strains constructed by reverse genetics technique were successful, which contained the HA and NA genes from H7N9 virus and six internal genes from the A/Puerto Rico/8/34 (PR8) virus (http://apps.who.int/iris/bitstream/10665/254827/1/WER9212.pdf?ua=1). Besides, several new types of vaccines are under development.

The A(H7N9) virus like particle (VLP) vaccine was developed consisting of full length, unmodified hemagglutinin (HA) and neuraminidase (NA) from the A/Anhui/1/2013 and the matrix1 (M1) protein from the A/Indonesia/05/2005 (H5N1) (Fries et al., 2013; Smith et al., 2013). The A/Anhui/1/2013 (H7N9) virus like particle (VLP) vaccine was produced in insect cells with the use of recombinant baculovirus. The H7N9 VLP can induce relatively high titers of $\mathrm{HI}$ antibodies against the homologous virus with any adjuvant. Besides, the H7N9 VLP could also elicit anti-neuraminidase (NA) antibody. A lethal murine wild-type A/Anhui/1/2013(H7N9) challenge demonstrated high survival of animals receiving the H7N9 VLP vaccine, the data demonstrate that recombinant $\mathrm{H} 7 \mathrm{~N} 9$ vaccine can be rapidly developed and was immunogenic and efficacious, supporting testing in men as a pandemic influenza $\mathrm{H} 7 \mathrm{~N} 9$ vaccine candidate (Smith et al., 2013).

Scientists developed and evaluated in ferrets an intranasal live attenuated influenza vaccine (LAIV) against H7N9 based on the A/Leningrad/134/17/57 (H2N2) cold-adapted master donor virus (Kong et al., 2015). It demonstrates that the LAIV is attenuated and safe in ferrets and induces high HA and NA inhibiting and virus-neutralizing titers. The antibodies against HA were also cross-reactive with divergent $\mathrm{H} 7$ strains. The H7N9 LAIV protects against severe disease and death and inhibits virus replication in ferret models.

Baxter has developed a non-adjuvant Vero cell culture-derived inactivated whole virus $\mathrm{H} 7 \mathrm{~N} 9$ vaccine using A/Anhui/1/2013(H7N9) (Wodal et al., 2015). The whole virus vaccine induced dose-dependent H7N9-specific HI, $\mathrm{MN}$ and NA antibodies in mice and guinea pigs. Immunized mice were protected against lethal H7N9 challenge in a dose-dependent manner. H7N9 and H1N1pdm09 vaccines were similarly immunogenic. Besides, an egg-derived influenza H7N9 reassortant was adapted in MDCK cells. Influenza H7N9 whole virus vaccine antigen was manufactured using microcarrier-based culture system. MDCK cell derived influenza H7N9 whole virus vaccine candidate is immunogenic and protective in ferrets (Chia et al., 2015).

A H7 DNA-H7N9 monovalent inactivated vaccine is safe and immunogenic prime-boost regimen in a randomized phase I clinical trial. The novel H7 DNA vaccine was safe, well-tolerated, and immunogenic when boosted with H7N9 monovalent inactivated vaccine, while priming for higher HAI and neutralizing antibody titers than H7N9 monovalent inactivated vaccine alone (Imai et al., 2017).

HA-based structural design approach is the first in the field to generate a recombinant replicative H7N9 virus (H7N9-53TM) showing broadened protection. The H7N9-53TM contains a replaced H3 HA transmembrane domain (TM) in its HA protein. In mice, the inactivated H7N9-53TM vaccine induced significantly higher HI titers, HA-specific IgG titers, and IFN- $\gamma$ production than the corresponding H7N9-53WT inactivated virus vaccine containing wild-type HA. Besides, mice immunized with the H7N9-53TM showed full protection against homologous (H7N9-53) and some protection against interclade H7N9 viruses (Wang et al., 2017b). The types and characteristics of human H7N9 vaccines have been shown in Table 2. 
Table 2 Types and characteristics of H7N9 vaccine

\begin{tabular}{cc}
\hline Vaccine types & Main characteristics \\
\hline H7N9 reverse genetics technique reassortant vaccine & Fast and applicable to HPAI. Be protected by patent \\
H7N9 VLP vaccine & Fast and safe. Lower immunogenicity \\
H7N9 LAIV & Wider range of cross protection effects \\
Vero cell culture-derived inactivated whole virus H7N9 vaccine & Vero cell is recommended by WHO as a substrate for vaccine production. \\
BDCK cell culture-derived inactivated whole virus H7N9 vaccine & MDCK cell is sensitive for influenza viruses. Potential tumor risk \\
H7 DNA-H7N9 monovalent inactivated vaccine & Fast. Lower immunogenicity \\
recombinant replicative H7N9 virus (H7N9-53TM) vaccine & New vaccine. To be tested by practice
\end{tabular}

\section{DRUG RESISTANT AND ALTERNATIVE DRUGS}

Because of the resistance to M2 blockers, the neuraminidase (NA) inhibitors (NAIs), particularly oseltamivir and peramivir, were used to mitigate disease severity among infected patients during the outbreak of influenza A(H7N9) infection. However, as with other antiviral drugs, the therapeutic benefit of NAIs can be compromised by the emergence of resistant virus variants. Since the outbreak of H7N9 in 2013, the resistant sites in NA of A(H7N9) virus isolated from patients have been reported: E119V, R292K, R152K (Wang et al., 2014) and A246T (Wang et al., 2016). These four drug resistance mutations in the NA protein have been detected in LPAI H7N9 virus. R292K had been detected in a HPAI H7N9 virus, A/Guangdong/17SF003/2016(SF003). The substitution of R292K in the NA protein in SF003 induced a mean 53,855-fold increase in the $\mathrm{IC}_{50}$ of oseltamivir, and a 3,556-fold and 73-fold increase in peramivir and zanamivir, respectively (Zhu et al., 2017). HPAI H7N9 viruses with $\mathrm{R} 292 \mathrm{~K}$ mutation in NA protein have been reported to be multiple drugs resistance (Zhu et al., 2017). Besides R292K, E119Vand H274Y were identified in HPAI H7N9 isolates from human (Yang et al., 2017).

In addition to the surveillance based on human infections, a number of scientists have also conducted other studies on H7N9 NA resistance mutations. One paper reported that influenza $\mathrm{A}(\mathrm{H} 7 \mathrm{~N} 9)$ virus acquires resistance-related neuraminidase I222T substitution when infected mallards are exposed to low levels of oseltamivir in water (Gillman et al., 2015). Scientists in St. Jude Children's Research Hospital used random mutagenesis to screen for mutations conferring reduced susceptibility to NAIs in avian N9 originating from A/Duck/Memphis/546/1974(H11N9) virus. The results showed that E119V, I222M, R292K, A246T, Q136K and H274Y in N9 could lead avian N9 virus resist to neuraminidase at different levels (Song et al., 2015). A recent research reported that 14 amino acid substitutions were introduced into the NA of A/Shanghai/2/2013(H7N9) and recombinant N9 (recN9) proteins were expressed in a baculovirus system. All substitutions conferred either re- duced or highly reduced inhibition by at least 1 NA inhibitor (Gubareva et al., 2017). H7N9 Neuraminidase resistance related loci are shown in Table 3.

As mentioned above, emergence of virus variants carrying markers of decreased susceptibility to neuraminidase inhibitors was reported in $\mathrm{A}(\mathrm{H} 7 \mathrm{~N} 9)$, it is therefore necessary to investigate whether other classes of drugs can control H7N9 infections. DAS181 is a recombinant fusion protein with sialidase activity, removes sialic acid-containing receptor from respiratory epithelial cells, preventing attachment and replication of influenza virus. DAS181 was shown to potently inhibited replication of wild-type influenza A(H7N9) and its oseltamivir-resistant R292K variants in mice (Marjuki et al., 2014). Ribavirin is a well-characterized, broad-spectrum nucleoside inhibitor used to halt the synthesis and capping of viral RNA and mRNA, respectively, by the viral RNA-dependent RNA polymerase. Research showed that ribavirin is effective against drug-resistant H7N9 influenza virus infections (Bi et al., 2016). Some researches on H7N9 virus transcriptomic characterization indicated that several kinase inhibitors, as well as FDA-approved drugs, such as troglitazone and minocycline which regulate the host response to A(H7N9) that may act as potential anti-virals (Josset et al., 2014).

\section{CONCLUSION}

From 2013 up to now, the majority of human infection with H7N9 are LPAI H7N9 virus, but recently some HPAI H7N9 virus strains have been detected in the fifth epidemic wave. The fifth epidemic wave occurred earlier, spread to more areas, and infected more people than in previous four epidemic waves. The clinical severity remains unchanged to date. At present, there is no conclusive evidence that the HPAI H7N9 virus is more pathogenic to experimental animal or human than LPAI H7N9 virus.

Vaccination is the primary measure to control the spread of influenza virus infection in humans. In March 2017, WHO recommended A/Hunan/2650/2016-like and A/Guangdong/17SF003/2016-like virus (HPAI) as additional candidate vaccine viruses. The multiple NA mutations related to 
Table 3 H7N9 Neuraminidase resistance related sites

\begin{tabular}{|c|c|c|}
\hline Amino acid substitution & Source of viruses/tested with & Reference \\
\hline E119V, R292K and R152K & LPAI H7N9 virus isolated from human & (Wang et al., 2014) \\
\hline A246T & LPAI H7N9 virus isolated from human & (Wang et al., 2016) \\
\hline R292K & $\begin{array}{l}\text { HPAI H7N9 virus isolated from human } \\
\text { (A/Guangdong/17SF003/2016(SF003)) }\end{array}$ & (Zhu et al., 2017) \\
\hline R292K, E119V, A246T and H274Y & HPAI H7N9 virus isolated from human & (Yang et al, 2017) \\
\hline $\mathrm{I} 222 \mathrm{~T}$ & $\begin{array}{l}\text { H7N9 virus isolated from mallard } \\
\text { exposed to oseltamivir in water }\end{array}$ & (Gillman et al., 2015) \\
\hline E119V, I222M, R292K, A246T, Q136K and H274Y & $\begin{array}{c}\text { N9 random mutagenesis from } \\
\text { A/Duck/Memphis/546/1974(H11N9)virus }\end{array}$ & (Song et al., 2015) \\
\hline $\begin{array}{l}\text { R289K, H271Y, I219R, I219K, R148K, T244P, N291S, R367K, } \\
\text { E115V, E115A, E115G, E115D, Q132K and E273D }\end{array}$ & $\begin{array}{c}\text { recNA from A/Shanghai/2/2013(H7N9) } \\
\text { virus }\end{array}$ & (Gubareva et al., 2017) \\
\hline
\end{tabular}

decreased susceptibility to neuraminidase inhibitors highlighted the critical role of alternative drugs research and development, and promising alternative drugs should be further developed and clinically tested.

It is difficult to predict the circulation level of $\mathrm{A}(\mathrm{H} 7 \mathrm{~N} 9)$ in the following seasons. Continuous surveillance in humans and avian species is of great importance. Some tools were developed by WHO for influenza related risk assessment (http://www.who.int/influenza/publications/TIPRA_manual_v1/en/; http://www.who.int/influenza/surveillance_monitoring/pisa/en/). Regular assessments of the epidemiological characteristics, virologial characteristics and clinical severity of human infections with avian influenza A H7N9 virus are necessary for pandemic risk assessment. In addition, computational methods can be used to analyse antigenic epitopes of avian influenza A (H7N9) viruses (Liu et al., 2015).

Compliance and ethics The author(s) declare that they have no conflict of interest.

Acknowledgements This work was supported by the National Key Research and Development Program of China (2016YFD0500208 to Dayan Wang). The contents of this article are solely the responsibility of the authors and do not necessarily represent the views of China CDC or other organizations.

Bi, Y., Wong, G., Liu, Y., Liu, L., Gao, G.F., and Shi, Y. (2016). Ribavirin is effective against drug-resistant H7N9 influenza virus infections. Protein Cell 7, 611-614

Chen, H., Liu, S., Liu, J., Chai, C., Mao, H., Yu, Z., Tang, Y., Zhu, G., Chen, H.X., Zhu, C., Shao, H., Tan, S., Wang, Q., Bi, Y., Zou, Z., Liu, G., Jin, T., Jiang, C., Gao, G.F., Peiris, M., Yu, H., and Chen, E. (2016). Nosocomial co-transmission of avian influenza $\mathrm{A}(\mathrm{H} 7 \mathrm{~N} 9)$ and $\mathrm{A}(\mathrm{H} 1 \mathrm{~N} 1) \mathrm{pdm} 09$ viruses between 2 patients with hematologic disorders. Emerg Infect Dis 22, 598-607.

Chia, M.Y., Hu, A.Y.C., Tseng, Y.F., Weng, T.C., Lai, C.C., Lin, J.Y., Chen, P.L., Wang, Y.F., Chao, S.R., Chang, J.Y., Hwang, Y.S., Yeh, C.T., Yu, C.P., Chen, Y.C., Su, I.J., and Lee, M.S. (2015). Evaluation of MDCK cell-derived influenza H7N9 vaccine candidates in ferrets. PLoS ONE 10, e0120793.

Fries, L.F., Smith, G.E., and Glenn, G.M. (2013). A recombinant viruslike particle influenza A (H7N9) vaccine. N Engl J Med 369, 2564-2566.
Gao, R., Cao, B., Hu, Y., Feng, Z., Wang, D., Hu, W., Chen, J., Jie, Z., Qiu, H., Xu, K., Xu, X., Lu, H., Zhu, W., Gao, Z., Xiang, N., Shen, Y., He, Z., Gu, Y., Zhang, Z., Yang, Y., Zhao, X., Zhou, L., Li, X., Zou, S., Zhang, Y., Li, X., Yang, L., Guo, J., Dong, J., Li, Q., Dong, L., Zhu, Y., Bai, T., Wang, S., Hao, P., Yang, W., Zhang, Y., Han, J., Yu, H., Li, D., Gao, G.F., Wu, G., Wang, Y., Yuan, Z., and Shu, Y. (2013). Human infection with a novel avian-origin influenza A (H7N9) virus. N Engl J Med 368, 1888-1897.

Gillman, A., Nykvist, M., Muradrasoli, S., Söderström, H., Wille, M., Daggfeldt, A., Bröjer, C., Waldenström, J., Olsen, B., and Järhult, J.D. (2015). Influenza A(H7N9) virus acquires resistance-related neuraminidase $\mathrm{I} 222 \mathrm{~T}$ substitution when infected mallards are exposed to low levels of oseltamivir in water. Antimicrob Agents Chemother 59, 5196-5202.

Gubareva, L.V., Sleeman, K., Guo, Z., Yang, H., Hodges, E., Davis, C.T., Baranovich, T., and Stevens, J. (2017). Drug susceptibility evaluation of an influenza A(H7N9) virus by analyzing recombinant neuraminidase proteins. J Infect Dis 216, S566-S574.

Hoffmann, J., Otte, A., Thiele, S., Lotter, H., Shu, Y., and Gabriel, G. (2015). Sex differences in H7N9 influenza A virus pathogenesis. Vaccine 33, 6949-6954.

Imai, M., Watanabe, T., Kiso, M., Nakajima, N., Yamayoshi, S., IwatsukiHorimoto, K., Hatta, M., Yamada, S., Ito, M., Sakai-Tagawa, Y., Shirakura, M., Takashita, E., Fujisaki, S., McBride, R., Thompson, A.J., Takahashi, K., Maemura, T., Mitake, H., Chiba, S., Zhong, G., Fan, S., Oishi, K., Yasuhara, A., Takada, K., Nakao, T., Fukuyama, S., Yamashita, M., Lopes, T.J.S., Neumann, G., Odagiri, T., Watanabe, S., Shu, Y., Paulson, J.C., Hasegawa, H., and Kawaoka, Y. (2017). A highly pathogenic avian H7N9 influenza virus isolated from a human is lethal in some ferrets infected via respiratory droplets. Cell Host Microbe 22, 615-626.

Jin, Y., Yu, D., Ren, H., Yin, Z., Huang, Z., Hu, M., Li, B., Zhou, W., Yue, J., and Liang, L. (2014). Phylogeography of avian influenza A H9N2 in China. BMC Genomics 15, 1110.

Josset, L., Zeng, H., Kelly, S.M., Tumpey, T.M., and Katze, M.G. (2014). Transcriptomic characterization of the novel avian-origin influenza A (H7N9) virus: specific host response and responses intermediate between avian ( $\mathrm{H} 5 \mathrm{~N} 1$ and $\mathrm{H} 7 \mathrm{~N} 7)$ and human $(\mathrm{H} 3 \mathrm{~N} 2)$ viruses and implications for treatment options. mBio 5, e01102-13-e01102-13.

Kong, H., Zhang, Q., Gu, C., Shi, J., Deng, G., Ma, S., Liu, J., Chen, P., Guan, Y., Jiang, Y., and Chen, H. (2015). A live attenuated vaccine prevents replication and transmission of H7N9 virus in mammals. Sci Rep 5,11233 .

Li, Q., Zhou, L., Zhou, M., Chen, Z., Li, F., Wu, H., Xiang, N., Chen, E., Tang, F., Wang, D., Meng, L., Hong, Z., Tu, W., Cao, Y., Li, L., Ding, F., Liu, B., Wang, M., Xie, R., Gao, R., Li, X., Bai, T., Zou, S., He, J., Hu, J., Xu, Y., Chai, C., Wang, S., Gao, Y., Jin, L., Zhang, Y., Luo, H., Yu, H., He, J., Li, Q., Wang, X., Gao, L., Pang, X., Liu, G., Yan, Y., Yuan, H., 
Shu, Y., Yang, W., Wang, Y., Wu, F., Uyeki, T.M., and Feng, Z. (2014). Epidemiology of human infections with avian influenza $A(H 7 N 9)$ virus in China. N Engl J Med 370, 520-532.

Liu, J., Xiao, H., Wu, Y., Liu, D., Qi, X., Shi, Y., and Gao, G.F. (2014). H7N9: a low pathogenic avian influenza A virus infecting humans. Curr Opin Virol 5, 91-97.

Liu, M., Song, T.R., Hua, S., Wu, A.P., and Jiang, T.J. (2015). Computational analysis of antigenic epitopes of avian influenza A (H7N9) viruses. Sci China Life Sci 58, 687-693.

Marjuki, H., Mishin, V.P., Chesnokov, A.P., De La Cruz, J.A., Fry, A.M., Villanueva, J., and Gubareva, L.V. (2014). An investigational antiviral drug, DAS181, effectively inhibits replication of zoonotic influenza A virus subtype H7N9 and protects mice from lethality. J Infect Dis 210, 435-440.

Mok, C.K.P., Lee, H.H.Y., Chan, M.C.W., Sia, S.F., Lestra, M., Nicholls, J.M., Zhu, H., Guan, Y., and Peiris, J.M.S. (2013). Pathogenicity of the novel A/H7N9 influenza virus in mice. mBio 4, e00362-13-e00362-13.

Qi, X., Qian, Y.H., Bao, C.J., Guo, X.L., Cui, L.B., Tang, F.Y., Ji, H., Huang, Y., Cai, P.Q., Lu, B., Xu, K., Shi, C., Zhu, F.C., Zhou, M.H., and Wang, H. (2013). Probable person to person transmission of novel avian influenza A (H7N9) virus in Eastern China, 2013: epidemiological investigation. BMJ 347, f4752-f4752.

Richard, M., Schrauwen, E.J.A., de Graaf, M., Bestebroer, T.M., Spronken, M.I.J., van Boheemen, S., de Meulder, D., Lexmond, P., Linster, M., Herfst, S., Smith, D.J., van den Brand, J.M., Burke, D.F., Kuiken, T., Rimmelzwaan, G.F., Osterhaus, A.D.M.E., and Fouchier, R.A.M. (2013). Limited airborne transmission of H7N9 influenza A virus between ferrets. Nature 501, 560-563.

Shi, J.Z., Deng, G.H., Liu, P.H., Zhou, J.P., Guan, L.Z., Li, W.H., Li, X.Y., Guo, J., Wang, G.J., Fan, J., Wang, J.L., Li, Y.Y., Jiang, Y.P., Liu, L.L., Tian, G.B., Li, C.J., and Chen, H.L. (2013). Isolation and characterization of $\mathrm{H} 7 \mathrm{~N} 9$ viruses from live poultry markets-implication of the source of current H7N9 infection in humans. Chin Sci Bull 58, 1857-1863.

Smith, G.E., Flyer, D.C., Raghunandan, R., Liu, Y., Wei, Z., Wu, Y., Kpamegan, E., Courbron, D., Fries Iii, L.F., and Glenn, G.M. (2013). Development of influenza H7N9 virus like particle (VLP) vaccine: homologous A/Anhui/1/2013 (H7N9) protection and heterologous $\mathrm{A} /$ chicken/Jalisco/CPA1/2012 (H7N3) cross-protection in vaccinated mice challenged with H7N9 virus. Vaccine 31, 4305-4313.

Song, M.S., Marathe, B.M., Kumar, G., Wong, S.S., Rubrum, A., Zanin, M., Choi, Y.K., Webster, R.G., Govorkova, E.A., and Webby, R.J. (2015). Unique determinants of neuraminidase inhibitor resistance among N3, N7, and N9 avian influenza viruses. J Virol 89, 10891-10900.

Wang, D., Yang, L., Gao, R., Zhang, X., Tan, Y., Wu, A., Zhu, W., Zhou, J., Zou, S., Li, X., Sun, Y., Zhang, Y., Liu, Y., Liu, T., Xiong, Y., Xu, J., Chen, L., Weng, Y., Qi, X., Guo, J., Li, X., Dong, J., Huang, W., Zhang, Y., Dong, L., Zhao, X., Liu, L., Lu, J., Lan, Y., Wei, H., Xin, L., Chen, Y., Xu, C., Chen, T., Zhu, Y., Jiang, T., Feng, Z.,Yang, W., Wang, Y., Zhu, H., Guan, Y., Gao, G., Li, D., Han, J., Wang, S., Wu, G., and Shu, Y. (2014). Genetic tuning of the novel avian influenza A(H7N9) virus during interspecies transmission, China, 2013. Euro Surveill 19, pii: 20836

Wang, D., Yang, L., Zhu, W., Zhang, Y., Zou, S., Bo, H., Gao, R., Dong, J., Huang, W., Guo, J., Li, Z., Zhao, X., Li, X., Xin, L., Zhou, J., Chen, T., Dong, L., Wei, H., Li, X., Liu, L., Tang, J., Lan, Y., Yang, J., and Shu, Y. (2016). Two outbreak sources of influenza A (H7N9) viruses have been established in China. J Virol 90, 5561-5573.

Wang, X., Jiang, H., Wu, P., Uyeki, T.M., Feng, L., Lai, S., Wang, L., Huo,
X., Xu, K., Chen, E., Wang, X., He, J., Kang, M., Zhang, R., Zhang, J., Wu, J., Hu, S., Zhang, H., Liu, X., Fu, W., Ou, J., Wu, S., Qin, Y., Zhang, Z., Shi, Y., Zhang, J., Artois, J., Fang, V.J., Zhu, H., Guan, Y., Gilbert, M., Horby, P.W., Leung, G.M., Gao, G.F., Cowling, B.J., and Yu, H. (2017a). Epidemiology of avian influenza A H7N9 virus in human beings across five epidemics in mainland China, 2013-17: an epidemiological study of laboratory-confirmed case series. Lancet Infect Dis 17, 822-832.

Wang, Y., Wu, J., Xue, C., Wu, Z., Lin, Y., Wei, Y., Wei, X., Qin, J., Zhang, Y., Wen, Z., Chen, L., Liu, G.D., and Cao, Y. (2017b). A recombinant H7N9 influenza vaccine with the $\mathrm{H} 7$ hemagglutinin transmembrane domain replaced by the $\mathrm{H} 3$ domain induces increased cross-reactive antibodies and improved interclade protection in mice. Antiviral Res 143, 97-105.

Wodal, W., Schwendinger, M.G., Savidis-Dacho, H., Crowe, B.A., Hohenadl, C., Fritz, R., Brühl, P., Portsmouth, D., Karner-Pichl, A., Balta, D., Grillberger, L., Kistner, O., Barrett, P.N., and Howard, M.K. (2015). Immunogenicity and protective efficacy of a vero cell culture-derived whole-virus H7N9 vaccine in mice and guinea pigs. PLoS ONE 10, e0113963.

Yang, J.R., and Liu, M.T. (2017). Human infection caused by an avian influenza A (H7N9) virus with a polybasic cleavage site in Taiwan, 2017. J Formosan Med Assoc 116, 210-212.

Yang, L., Zhu, W., Li, X., Chen, M., Wu, J., Yu, P., Qi, S., Huang, Y., Shi, W., Dong, J., Zhao, X., Huang, W., Li, Z., Zeng, X., Bo, H., Chen, T., Chen, W., Liu, J., Zhang, Y., Liang, Z., Shi, W., Shu, Y., and Wang, D. (2017). Genesis and spread of newly emerged highly pathogenic H7N9 avian viruses in mainland China. J Virol in press doi: 10.1128/JVI.01277-17.

Zhang, F., Bi, Y., Wang, J., Wong, G., Shi, W., Hu, F., Yang, Y., Yang, L., Deng, X., Jiang, S., He, X., Liu, Y., Yin, C., Zhong, N., and Gao, G.F. (2017). Human infections with recently-emerging highly pathogenic H7N9 avian influenza virus in China. J Infect 75, 71-75.

Zhou, J., Wang, D., Gao, R., Zhao, B., Song, J., Qi, X., Zhang, Y., Shi, Y., Yang, L., Zhu, W., Bai, T., Qin, K., Lan, Y., Zou, S., Guo, J., Dong, J., Dong, L., Zhang, Y., Wei, H., Li, X., Lu, J., Liu, L., Zhao, X., Li, X., Huang, W., Wen, L., Bo, H., Xin, L., Chen, Y., Xu, C., Pei, Y., Yang, Y., Zhang, X., Wang, S., Feng, Z., Han, J., Yang, W., Gao, G.F., Wu, G., Li, D., Wang, Y., and Shu, Y. (2013). Biological features of novel avian influenza A (H7N9) virus. Nature 499, 500-503.

Zhou, L., Tan, Y., Kang, M., Liu, F., Ren, R., Wang, Y., Chen, T., Yang, Y., Li, C., Wu, J., Zhang, H., Li, D., Greene, C.M., Zhou, S., Iuliano, A.D., Havers, F., Ni, D., Wang, D., Feng, Z., Uyeki, T.M., and Li, Q. (2017). Preliminary epidemiology of human infections with highly pathogenic avian influenza $\mathrm{A}(\mathrm{H} 7 \mathrm{~N} 9)$ virus, China, 2017. Emerg Infect Dis 23, $1355-1359$.

Zhu, H., Wang, D., Kelvin, D.J., Li, L., Zheng, Z., Yoon, S.W., Wong, S.S., Farooqui, A., Wang, J., Banner, D., Chen, R., Zheng, R., Zhou, J., Zhang, Y., Hong, W., Dong, W., Cai, Q., Roehrl, M.H.A., Huang, S.S.H., Kelvin, A.A., Yao, T., Zhou, B., Chen, X., Leung, G.M., Poon, L.L.M., Webster, R.G., Webby, R.J., Peiris, J.S.M., Guan, Y., and Shu, Y. (2013). Infectivity, transmission, and pathology of human-isolated H7N9 influenza virus in ferrets and pigs. Science 341, 183-186.

Zhu, W., Zhou, J., Li, Z., Yang, L., Li, X., Huang, W., Zou, S., Chen, W., Wei, H., Tang, J., Liu, L., Dong, J., Wang, D., and Shu, Y. (2017). Biological characterisation of the emerged highly pathogenic avian influenza (HPAI) A(H7N9) viruses in humans, in mainland China, 2016 to 2017. Euro Surveill 22, 30533.

Zhuang, Q.Y., Wang, S.C., Wu, M.L., Liu, S., Jiang, W.M., Hou, G.Y., Li, J.P., Wang, K.C., Yu, J.M., Chen, J.M., and Chen, J.W. (2013). Epidemiological and risk analysis of the H7N9 subtype influenza outbreak in China at its early stage. Chin Sci Bull 58, 3183-3187. 